\title{
Human capital inequality, population mobility and regional economic growth--An Empirical Study Based on China
}

\author{
Yuke Li \\ School of International Studies, University of International Business and Economics, Beijing, 100029, China
}

Keywords: Economic growth; human capital inequality; population mobility

\begin{abstract}
Based on the Gini coefficient of human capital in 2004 and the per capita GDP data from 2005 to 2015, this paper analyses the relationship between the inequality of human capital and the long-term growth rate of regional economy. During the period of this analysis, the degree of human capital inequality has a positive impact on the rate of economic growth. Combined with the previous literature, the results show that China's economic growth in this period is still mainly dependent on fixed assets rather than human capital.
\end{abstract}

\section{Introduction}

Human capital has always played a crucial role in economic development. Education is an important manifestation of human capital, but also an important way for the formation of human capital in a country. Many theories and studies of economics also present the important role of human capital in economic growth. For example, Lucas (1988) once said the size of the human capital stock for the economic growth rate played a fundamental role in macro growth model. There are also a series of empirical studies on national economic development which confirm this theoretical prediction. These studies are primarily concerned with the impact of the total amount of human capital on economic growth; they have begun to focus on the role of human capital distribution in the process of economic growth by subsequent studies. From the intuition of economics, inequality in the distribution of educational resources leads to inequality in the distribution of human capital, and human capital as an important element of social production, will directly affect the individual's income, wealth and status. Correspondingly, inequality in human capital affects the process of economic development. In other words, even given the same average human capital level, the different distribution of human capital will have different effects on the level of economic development and growth rate.

From another point of view, we can also regard human capital inequality as a good measure of social inequality. Economists use income inequality or wealth inequality to measure the inequality of society. However, the income inequality may have high measurement errors. The inequality of wealth is also limited by the availability of data, making it difficult for economists to comprehensively analyze the inequalities in different countries or in different regions of the same country. In this case, the inequality of human capital provides a good indicator for studying the relationship between inequality and regional economic development. Human capital such as education is highly related to the wealth and social status of individuals and families, and is able to better measure the overall development potential of individuals, which is measured by indicators such as education also has better data availability. There are many domestic and foreign researches through empirical data to test the degree of inequality of human capital and the relationship between economic development levels.

The author believes that only consider the degree of inequality and economic development is not comprehensive in thinking about this issue. The world today is an open, circulation economy of the world in which human resources and capital can flow freely between different countries, which mean that a country's human capital inequality is likely to be related with the human resource flows. 
When we analyze the growth differences within a country, this problem will still exist. The relatively free labor force between the provinces affects the distribution of human capital. From this we can assume that the impact of human capital inequality on economic growth may be different between the flows of labor. This paper attempts to use the data of China's provincial human capital and economic growth to study this issue.

\section{The data and measurement model of this subject}

The paper focus on long-term economic growth rather than the same level of economic, because it is difficult to determine the human capital inequality change the economic level, or the economic level changes the human capital inequality, the degree of inequality of human capital has also undergone a corresponding change, so the estimated results can only be described as accurate, and it is difficult to completely defined as causal. Therefore, this paper attempts to explore the relationship between the degree of human capital inequality at a certain stage and the growth rate of per capital GDP.The author believes that the flow of human resources in the domestic market gradually liberalized, especially highly educated talent has a greater choice of geographical freedom, which may lead to human capital inequality. For example, we may divide the Northeast into the eastern part, but according to the facts and data that we can observe, the Northeast is actually in the whole as a human resource outflow provinces. This suggests that simply comparing the relationship between human capital and economic growth based on geographical location may not help us to identify the underlying mechanisms.

Because the main concern of this article is the growth rate of GDP per capita in different regions over a long period of time, the per capita GDP level or its growth rate in the same period, so the authors use the per capita GDP data of each province to calculate the 2005-2008, 2005 -2010, 2005-2015 3-year, 5-year 10-year average per capita GDP growth rate. This paper mainly uses the following regression equation:

i represents the i-th province, and growth represents the average growth rate of GDP per capita in a given period of time. A is a constant term, gini04 represents the Gini coefficient of the human capital distribution in 2004, and the data comes from the "China Statistical Yearbook". The Gini coefficient is in the range of 0 to 1 , the value is larger, the distribution of human capital in the province's population is more unequal, flowout represents the province's household population outflow of the proportion of the province's residents. Gini04 * flowout is the cross item we care about, and the coefficient $\delta$ represents the difference between the impact of the Gini coefficient on the long-term economic growth rate and whether the size of the population is affected by the size of the population.

Table 1. Descriptive statistical tables of key variables

\begin{tabular}{|c|c|c|c|c|c|c|c|}
\hline Variables | Number & Mean & \multicolumn{2}{|c|}{ Standard deviation } & \multicolumn{2}{|c|}{ Minimum } & \multicolumn{2}{|c|}{ Maximum } \\
\hline gini04| & 0.2452 & 2032 & 2899 & & 1829 & & 4437 \\
\hline Out of the population (\%)| & 31 & 2.300968 & 6.2 & 38576 & & -8.45 & 14.07 \\
\hline $05-08$ growth rate $(\%) \mid$ & 31 & 0.1864852 & 0.040 & & 0.09147 & 788 & 0.2876828 \\
\hline $05-10$ growth rate $(\%)$ & 31 & 0.1677497 & 0.0344 & 36 & 0.0812 & 588 & 0.2372456 \\
\hline $05-15$ growth rate $(\%) \mid$ & 31 & 0.1352681 & 0.025 & 7299 & 0.072 & 2653 & 0.1943833 \\
\hline
\end{tabular}

It can be seen from the table that the Gini coefficient of the provincial capital in 2004 is basically distributed near the mean (the standard deviation is small), but there is still a big gap between the minimum and the maximum. The research cited earlier in this paper points out that the relationship between human capital inequality and economic development may be different in different regions, but these studies do not develop into the possible causes of the differences in this geographical division.

The possible factor is that the flow of human resources in different regions is different from that of the outflows. If the province's human capital is largely outflowed, the province's human capital 
may have less impact on economic development and the province's economic development is more dependent on fixed capital investment.

There is also another possibility that if inequality actually shows a positive effect on the rate of economic growth, then the provinces that man outflows may be more "backward" than influent provinces. This conjecture is basically consistent with the relationship between people's mobility and economic development in different regions of China, but the specific relationship also requires the empirical results of this paper to be tested.

\section{The regression results and analysis}

This section mainly reports the regression results of the metrological models. As a reference standard, this paper first estimates a model that does not include the flow out of population variables. On this basis, this paper estimates the model with all the parameters, and the results reported in Table as follows:

Table 2. The relationship between human capital inequality and long-term economic growth, and regional differences in population movements

\begin{tabular}{|c|c|c|c|c|c|c|}
\hline VARIABLES & $\begin{array}{c}(1) \\
\text { growth_05 } \\
08\end{array}$ & $\begin{array}{c}(2) \\
\text { growth_05 } \\
10\end{array}$ & $\begin{array}{c}\text { (3) } \\
\text { growth_05 } \\
15\end{array}$ & $\begin{array}{c}(4) \\
\text { growth_05 } \\
08\end{array}$ & $\begin{array}{c}(5) \\
\text { growth_05 } \\
10\end{array}$ & $\begin{array}{c}(6) \\
\text { growth_05 } \\
15\end{array}$ \\
\hline gini04 & $\begin{array}{l}0.0550 \\
(0.144)\end{array}$ & $\begin{array}{l}0.0611 \\
(0.122)\end{array}$ & $\begin{array}{c}0.150^{*} \\
(0.0870)\end{array}$ & $\begin{array}{l}0.0790 \\
(0.146)\end{array}$ & $\begin{array}{l}0.0866 \\
(0.120)\end{array}$ & $\begin{array}{l}0.179 * * \\
(0.0790)\end{array}$ \\
\hline flowout & & & & $\begin{array}{l}-0.00315 \\
(0.00883)\end{array}$ & $\begin{array}{l}-0.00115 \\
(0.00725)\end{array}$ & $\begin{array}{c}-0.00296 \\
(0.00477)\end{array}$ \\
\hline $\begin{array}{c}\text { gini04*flowo } \\
\text { ut }\end{array}$ & & & & $\begin{array}{c}0.0187 \\
(0.0357)\end{array}$ & $\begin{array}{c}0.0120 \\
(0.0293)\end{array}$ & $\begin{array}{c}0.0196 \\
(0.0193)\end{array}$ \\
\hline Constant & $\begin{array}{c}0.173^{* * *} \\
(0.0361)\end{array}$ & $\begin{array}{c}0.153^{* * *} \\
(0.0305)\end{array}$ & $\begin{array}{c}0.0984^{* * *} \\
(0.0218)\end{array}$ & $\begin{array}{c}0.164^{* * *} \\
(0.0369)\end{array}$ & $\begin{array}{c}0.143^{* * *} \\
(0.0303)\end{array}$ & $\begin{array}{c}0.0876^{* * *} \\
(0.0199)\end{array}$ \\
\hline Observations & 31 & 31 & 31 & 31 & 31 & 31 \\
\hline R-squared & 0.005 & 0.009 & 0.093 & 0.063 & 0.119 & 0.318 \\
\hline
\end{tabular}

Column one and Column four is the regression results of average per capital GDP growth rate between 2005-2008.Column two and Column five is the regression results of average per capital GDP growth rate between 2005-2010.Column three and Column six is the regression results of average per capital GDP growth rate between 2005-2015.As can be seen from the results of the table, the inequality of human capital generally shows a positive correlation with the long-term economic growth rate.

We can conclude that: first, at the present stage of economic development in China, the inequality of human capital still has a positive effect on the speed of economic development, the accumulation of fixed assets is still the main driving force of the current economic development (2005-2015 stage), which is basically consistent with our understanding and common sense of the Chinese economy; Second, the impact of human capital inequality on economic growth is mainly manifested in the long term.

After adding the population outflow ratio and the cross item, we can see that the above model basically does not change, but the regression of the $\mathrm{R}$ side has been a substantial increase, indicating that the model greatly enhanced the explanatory power. And the coefficient of the cross is also positive, which indicates that this conclusion also has certain universality. Furthermore, the authors found that the correlation coefficient between the flowout variable and the cross term was 0.9904, indicating that the significant value of the regression coefficient was probably due to collinearity. Therefore, the authors further examine the joint significance of the two variable coefficients. The results of this paper prove to a certain extent the differences between different regions. In general, 
in conjunction with previous assumptions, we can argue that inequality has a positive effect on economic growth, and that the size of this role is relatively greater for provinces that are out of the population.

\section{Conclusions}

The relationship between human capital and long-term economic growth, both in macroeconomic and economic development, is a very important topic.On the basis of previous research, this paper explores the relationship between the human capital inequality and the average speed of per capita GDP growth in China's provinces from 2005 to 2015, and the change of this relationship with the form of population movement.The results of this paper show that long-term human capital inequality and the average economic growth is still showing a positive relationship, indicating that China's economic growth at this stage is still mainly driven by fixed capital investment. In addition, this effect is even more important for provinces with population outflows, which suggests that the pattern of population outflows is closer to fixed capital investment and it does not make good use of the province's human capital.

It is worth noting that the results of this paper do not mean that we need to improve the inequality of human capital to promote economic growth. The conclusion of this paper reveals that, in the context of the current economic transformation and upgrading environment, an important dimension of changing the development model is how to improve the role of human capital in economic growth. Whether it is at the national level, or the local provinces, only by encouraging innovation, industrial upgrading and other ways to continue to make human capital to effectively promote the role of economic growth, China's economy may enter the next stage of more healthy development.

In addition, the article only attempts to explore the potential mechanism of the flow of human capital, but there may be many other mechanisms which will also affect the relationship between human capital inequality and long-term economic development, such as industrial structure, policy factors and so on. Studying the impact of these different factors can better help us understand the relationship between the distribution of human capital in different regions and economic growth, which is worth exploring further in the future.

\section{References}

[1] Galore, Moab. (2004). from physical to human capital accumulation: Inequality and the process of development. The Review of Economic Studies, 71(4), 1001-1026. [2] Lopez, Thomas. (1998). addressing the education puzzle: the distribution of education and economic reform (No. 2031). 2015 (09): 198-200.

[3] Lucas, R. E. (1988). On the mechanics of economic development. Journal of Monetary Economics, 22(1), 3-42 